\title{
DÜBLIN
}

Technological University Dublin

ARROW@TU Dublin

\section{The benefits of task and cognitive workload support for operators in ground handling}

\author{
Maria Chiara Leva \\ Technological University Dublin, maria.leva@tudublin.ie \\ Yilmar Builes \\ Trinity College Dublin, Ireland
}

Follow this and additional works at: https://arrow.tudublin.ie/schfsehcon

Part of the Computer Sciences Commons, and the Medicine and Health Sciences Commons

\section{Recommended Citation}

Leva, Maria \& Builes, Yilmar. (2017). The Benefits of Task and Cognitive Workload Support for Operators in Ground Handling. 225-238. 10.1007/978-3-319-61061-0_15.

This Conference Paper is brought to you for free and open access by the School of Food Science and Environmental Health at ARROW@TU Dublin. It has been accepted for inclusion in Conference papers by an authorized administrator of ARROW@TU Dublin. For more information, please contact arrow.admin@tudublin.ie, aisling.coyne@tudublin.ie,gerard.connolly@tudublin.ie.

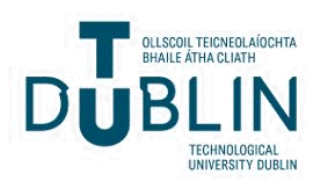


See discussions, stats, and author profiles for this publication at: https://www.researchgate.net/publication/318145384

\section{The Benefits of Task and Cognitive Workload Support for Operators in Ground Handling}

Conference Paper in Communications in Computer and Information Science · June 2017

Dol: 10.1007/978-3-319-61061-0_15

CITATION

2 authors, including:

8. Maria Chiara Leva

Technological University Dublin - City Campus

113 PUBLICATIONS 535 CITATIONS

SEE PROFILE

Some of the authors of this publication are also working on these related projects:

READS

125

Project Tosca: Total Safety Management for safety critical activities View project

DIAMOND: Revealing actionable knowledge from data for more inclusive and efficient transport systems (https://diamond-project.eu) View project 


\title{
THE BENEFITS OF TASK AND COGNITIVE WORKLOAD SUPPORT FOR OPERATORS IN GROUND HANDLING
}

\author{
M. C. Leva ${ }^{1}$, Y. Builes ${ }^{2}$, \\ ${ }^{1}$ Dublin Institute of Technology School of Environmental Science Dublin Ireland. \\ ${ }^{2}$ Tosca Solutions ltd, The Tower, Trinity Technology \& Enterprise Centre, Pearse Street, \\ Dublin, Ireland
}

\begin{abstract}
The scope of the present work is to report an action research project applied to the relationship of task and cognitive workload support on one of the most important aspects of an airport: ground handling. At the beginning of the project workload management was not in the scope of work but as the project progressed and preliminary results and feedback were gained the researcher came to realize that some form of workload management support was also achieved as a by-product. The present paper is an attempt to account for what was achieved and how. Safe and efficient ground handling during departure and arrival of an aircraft requires coordinated responsibilities amongst qualified operators collaborating together simultaneously in a time constrained environment. The context is one of medium-high workload due to the number of activities covered in a short time, such as: passenger, baggage and cargo handling, aircraft loading, the provision and use of ground support equipment, etc. This paper presents the introduction of a tool aimed at performance monitoring and task support and discusses how the use of it can play a key role in the adequate management of workload by operators in Ground Handling. The core elements of the tool under analysis are electronic checklist and digitized shift handover, and it aims at highlighting how they have impacted performance, reducing operational and human related issues.
\end{abstract}

Keywords: Performance Management, Safety Management, Cognitive Workload, Task Support, electronic Checklist, Shift Handover, Aviation.

\section{Introduction: Ground Operations and Human Workload}

In aviation, ground operations is the aspect that deals with the airport handling procedures ensuring passengers and baggage are safely on board the aircraft prior to departure [1]. Safe and efficient ground handling during departure and arrival of an aircraft requires coordinated responsibilities amongst qualified persons at the same time, which generates heavy workload due to the high number of activities covered in a short time, such as: passenger, baggage and cargo handling, aircraft loading and 
handling, baggage preparation for loading and weight and balance sheet, use of ground support equipment, etc. [1]

The effects of task demands on human performance are increasingly under the spotlight, as the move towards automation has shifted the nature of human work from working with the body to working more with the mind. Furthermore the increased responsibilities transferred to complex technological tools along with more complex procedures have imposed more demands on operators [2]. Instead of physical endurance and strength, sustained attention and problem solving skills have become more important [3]. This element is relevant for ground operations together with the observed effect of how physically demanding work that is performed simultaneously with a cognitive task can influence mental workload by weakening mental processing or decreasing performance [4]. In this context the aim of this paper is to explore the benefits of a web based application developed as a form of task support in ground handling tasks. Specifically the initiative introduced in a regional airport the use of an electronic checklist and shift handover as key element in fostering a safer and more efficient work environment. The digitization of daily electronic checklist and support systems for the shift handover which list the operations of the "turnaround" to be performed for each aircraft, and other maintenance activities required for equipment and/or infrastructure (e.g. runway inspections) was a platform able to provide the opportunity to collect real time performance and reporting on day to day anomalies and issues that was not available before. The tool has been used for two years and in this study we collected feedback from front line personnel and management on what were the perceived impacts the tool had on performance. At the beginning of the project workload management was in fact not in the scope of work but as the project progressed and preliminary results and feedback was gained the researcher came to realize that some form of workload management support was also achieved as a byproduct. The present paper is an attempt to account for what was achieved and how.

\subsection{Cognitive Workload and Task Support}

A comprehensive definition of cognitive workload is "an amount of mental resources required to perform a specific task or sequence of tasks in a given environment" [5]. Excessive cognitive workload is generated when the satisfactory performance of a task demands from the operator more resources than are available at any given time [6].

A task can become complex after simple manipulations, for example, increasing the number of elements, changing the number of decisions required to complete an action, or the display duration as these changes can influence attention, effectiveness, and the time needed to complete a task [7].

The assignment of additional tasks to a worker has been one of the workload manipulations most commonly done even when the individual is already performing a complex task. The use of executive control processes becomes essential to guarantee the successful performance of multiple concurrent tasks [8].

The successful execution of several tasks simultaneously is more vulnerable as the workload increases. The workload is shouldered by the cognitive capability known as 'executive functions'. Executive functions are necessary for goal-directed behavior, as 
they include the ability to initiate and stop actions, to monitor and change behaviors, to plan future actions when faced with new situations [8]. A task support in this sense can be one able to sustain some of the executive functions such as working memory (that has to do with the capacity to hold and manipulate information "on-line" in real time) and sequencing (the ability to break down complex actions into manageable units and prioritize them).

To do so a necessary cornerstone is a clear task description. Task analysis in this sense is a necessary requirement to the design of task support. A proper acquisition of relevant information about a task in a safety-critical environment is the foundation of every sound human factor analysis. More and more studies have highlighted that this critical first step of the analysis cannot be neglected as it needs to provide the design stage with structured information about the tasks and contexts to be addressed, particularly when there are relevant time constraints during workload. This step of the study was carried out using a tool previously developed to support data collection and able to provide a structure for the interviews with the workers based on a simultaneous graphical representation of the task. It was used as a common means of communication between the technical personnel involved in the interviews \& the human factors practitioners involved in the action research. This was aimed at supporting a common understanding of the tasks, their main objectives, challenges and criticalities whilst performing the actual task description [9]. The task analysis lead to the development of revised check lists for the key turnaround tasks and to the inclusion of shift handover provisions for the other activities not covered by checklists and not related to flight turnaround time. The checklists were used as a real time sign off for the tasks and delivered task support as they reminded key steps in detail and gave the possibility to report quickly any possible anomalies or issues in carrying out the tasks. Furthermore the shift handover page was designed to give the possibility to allocate tasks outside peak time, check status quickly and report once again issues as they arise. The information is managed by back office and feedback can be provided through the same dashboard where the shift handover occurs. We will discuss in the following paragraph the rationale for these very simple choices and their current outcomes

\section{Electronic checklist and shift handover: their role for task support \& workload management}

The National Transportation Safety Board of United States recommends the use of checklist to carry out highly proceduralised work such as for instance the proper aircraft configuration for each phase of the flight. However, the improper use of these items can be a contributing factor to incidents and accidents [10]. The paper checklists that have been digitised were however already in use at the airport where the study occurred and they were exposed to a number of design weaknesses [11]. The most relevant issues included the inability to mark skipped items or the lack of a pointer for each item, and the lack of support for switching between several checklists. All these obstacles were mitigated with the use of an electronic checklist [11]. 
Electronic checklists offer several benefits to support a faster execution as they supply an external memory support for pending or completed steps of a procedure as well as serving as a reminder of omitted steps. At the same time, the electronic checklist can "detect" and show the current status for every single procedure. This can support status awareness for long tasks and help to ensure the completion and control of many simultaneous tasks. The incorporation of a touch-operated function into the electronic checklist also permit a faster information manipulation in switching from one procedure to another without losing track of partially completed checklists or getting lost through many tasks.

The electronic checklist system was designed specially to reduce four types of common errors present in traditional paper checklists. Firstly, as a help to avoid forgetting the tasks at hand, and avoid skipping tasks. Secondly, it is inevitable to suffer from distractions or interruptions during a day's work, an electronic checklist can minimise the issue, supporting the resumption of work after any interruption/distraction. Thirdly, share the information in real time, asking support to someone if it is necessary and last but not least offer data analytics on daily performance KPI, key issues and need for solutions, it also offer insight into how a solution seems to work on the shop floor after implemented [11].

Just as the electronic checklists play an important role to guarantee the proper performance of the tasks connected with aircraft turnaround, in the same way electronic shift handovers are an important factor for non-recurrent tasks, safety critical activities such as runway inspections and coordination between operators at various level (passengers handling operators and ramp operators with airport duty manager).

The importance of proper shift handovers is often discovered in accident analysis where improper communications and assignment transfer occurred between shifts. In 2005 for instance Texas City submitted the final investigation report about the fatal Isomerization Unit Explosion in its city; the report explicitly mention poor shift handover as a key root cause of the accident [12]. Reliable communication is crucial for safety critical tasks and a proper shift handover is highly relevant in this context [13]. This is why the Health and Safety Executive in the UK [13] has contributed a guidance document HSG48 in which they provide information to improve shift handover. The most relevant advice consists in specifying the information more carefully before it is communicated, including aids such as semi structured log books that are a task support of sort for the activity of communicating the right information about the non-recurrent tasks handed over from one shift to the next.

NASA demonstrated in a study how the design weaknesses of the traditional checklist and the improper human interactions associated with it can reduce the effectiveness of procedures, especially in complex socio technical systems where the role of the human is key. The same study also points out that merely improving the engineering design and the procedural sequence of the checklist will not eliminate the problem [11].

A recent report from the Aviation Safety Reporting System (ASRS) published in September 2015 highlights how the implementation of a new working methodology supported with a proper checklist has allowed the orderly execution and sequential collection of vital steps as well as facilitating the resolution of abnormal situations. Nevertheless, ASRS still receives incident reports associated with checklist errors, 
perhaps it's worth taking another look at some of the factors affecting proper checklist usage, including workers commitment and engagement [14].

\section{The user participation in developing the task support tool}

The design of a workspace and associated task is one of the key drivers to allow people to carry out their role in an organization effectively and enjoy their work. Inspection methods can be applied in Human Computer Interface design to assess usability of interactive systems. However, they do not consider the state of the operator while executing a task, the surrounding environment and the task demands [15]. As a result, all too frequently, heavy troubleshooting is still necessary in the real-world during the ramp-up phase once the system has been build. Furthermore, the involvement and commitment of staff is crucial to ensure ownership of any task support tool. Participatory design is a process based upon involving front line staff in assessing the workplace including activities and tools at an early stage to ensure feedback is incorporated into user informed design choices. It provides a good platform to enhance frontline staff's awareness and involvement in activity management, by allowing them to take control of the necessary knowledge and an understanding even of the risk involved in their day to day activities [16].

The IT system developed as part of this study in the regional airport was delivered in 2014. Its aim was to support performance management and change in the airport considering the challenges faced in commercial aviation: the need to grow traffic, increase effectiveness of existing staff as there was no budget to upscale resources to match the required traffic increase. This situation can potentially lead to increased workload and time pressure for operators during turnaround.

The operators suggested to adopt for their day to day a more organised approach to task assignment similar to the one used in the past for short-term periods of significant traffic growth due to special events (such as extra chartered flight during Mediterranean Olympic games in the region). This led to the development of a new integrated platform where operators at all levels could share all their required tasks, information and indicators in functional processes to create the transport service [17]. The case study involved University researchers and the staff of a small regional airport in Italy. The final result was an IT tool called "Daily Journal" configured as a databased to support, monitor and analyse day to day performance on the key activities in the airport. To start the process a mock-up was built to single out all the data that needed to be migrated form the paper format of the check lists used by Ramp and Operations for each flight into an electronic format.

Furthermore the data collected was extended to incorporate the managing of small deviations and anomalies. The previous paper forms were simple checklist that did not collect any info regarding who performed a task, if the task had any issues, or if there was the need to pass on any follow up or request for interventions from one shift to the next.

The checklist was restructured around the subtask performed for Ramp and Handling operations identified during the process mapping exercise. Furthermore it is now possible to record who is in each turn and who are the shift leaders, and any 
possible anomaly that might occur during the operations and its associated criticality level and follow up. Critical anomalies can be escalated into accident reporting at any point.

Additionally, this tool also supports the management of the Safety Assessment of existing and planned operations. This feeds into the reporting against key performance indicators required by the Airport Council international for benchmarking purposes [19]. The Daily Journal provides an integrated platform for performance monitoring, reporting, task support, procedure documentation and proactive risk assessment. Proactive risk assessment is required by ICAO guidance document on Safety management systems [18].

To guarantee a proper shift handover design, a mock-up was built to single out all the data that needed to be migrated from the paper format of the checklists used by Ramp and Operations for each flight into an electronic format [17]. The checklist was structured around the subtask performed for Ramp and Handling operations identified during the process mapping exercise. The system has been built as a management system and it is configured as a Web Application. The application is connected to the existing company's databases and can show all required data using an interface protected by password [17].

\section{Daily Journal in Operation: how it supports ground handling operators' workload concretely}

Before the Daily Journal implementation it was found that the airport activities were perceived as constant firefighting, and the majority of the people interviewed pointed out that there was no clear assignments of roles and responsibilities for each turn. $70 \%$ of people interviewed proposed a use of shift planning around each flight which was the method used for short-term periods of significant traffic growth due to special events. Among the suggestions it was also proposed to allow automatic collection of data for ground handling task performance for every turnaround (already manually collected with the Trip File associated to each flight). Around $80 \%$ of people interviewed said that there wasn't a clear form of performance appraisal and they would have liked to have one.

One of the main change management activities carried out was to mitigate these issues providing an electronic checklist about what needs to be done by whom, so that the process of turnaround in ground handling can be integrally monitored. Fig. 1 shows a checklist for a flight that arrives, where for each operation the sign off requires to select the name of the operator that executed it. There is the option to open a sub-task located to the right, where it can insert the anomalies that can happen during the execution of a step, and classify them by giving a kind of "severity" and insert them in the context of the impact on safety, quality, security or environment, etc. The prototype can be used in at least three PC workstations, two in the Airport Duty Manager (ADM) office, situated in front of the aircraft parking apron and one in the ramp station, also located in front of the apron. The turnaround display is user friendly and easy to handle which allows users to enter information in a short time and share it instantly. 


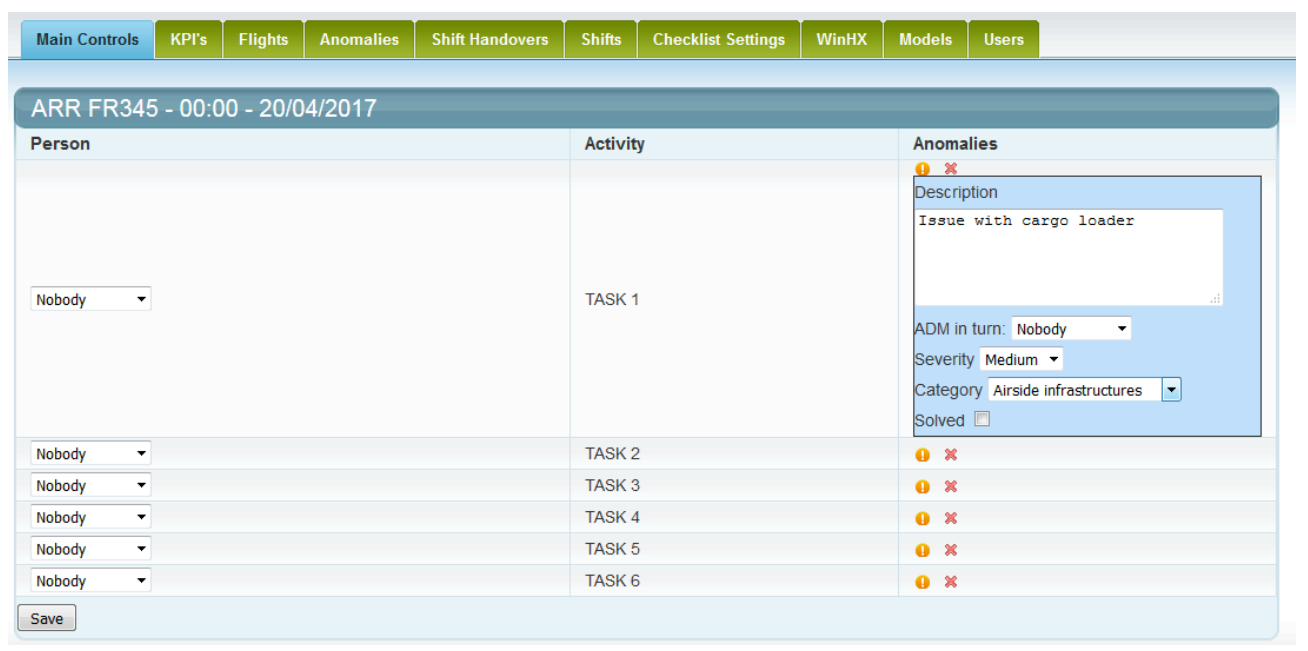

Fig. 1. Example of a checklist to monitor operations on incoming flights.

Fig. 2 shows the main screen of the Daily Journal, where all flights arriving and departing daily should be loaded automatically. Several items have been grouped into a single box called "Actions" for each flight. The first item corresponds to "checklists" with all the operations and the operators involved in the flight. The second item allows users to add cases of passengers with reduced mobility or those need of assistance. The third element includes loading instructions and the last one is used to insert the "anomalies". The main screen also shows the activities derived from handovers (shift handovers). The reporting around those activities is completed by the airport-duty-managers. He/she may also report problems even when they have already been investigated and resolved. Any abnormality reported remains in the system, even if it has been resolved, and they are analyzed and discussed during scheduled during management review meetings.

\begin{tabular}{|c|c|c|c|c|c|c|c|c|}
\hline \multicolumn{8}{|c|}{ Arrivals } & \multirow{2}{*}{$\begin{array}{c}\text { Thu, } 20 \\
\text { Apr } 2017\end{array}$} \\
\hline Fly No. & AIC REG & STA & ATA & From & Delay Code & Notes & Actions & \\
\hline \multicolumn{8}{|c|}{ ADDNEW } & \multirow{2}{*}{$\begin{array}{l}\text { Apr } 2017 \text { > } \\
\text { sun monture wed thu fri sat }\end{array}$} \\
\hline \multicolumn{8}{|c|}{ Departures } & \\
\hline Fly No. & AC REG & STD & ATD & To & Delay Code & Notes & Actions & \multirow{4}{*}{\begin{tabular}{|l|l|l|l|l|l|l|}
2 & 3 & 4 & 5 & 6 & 7 & 8 \\
9 & 10 & 11 & 12 & 13 & 14 & 15 \\
16 & 17 & 18 & 19 & 20 & 21 & 22 \\
23 & 24 & 25 & 26 & 27 & 28 & 29 \\
30 & & & & & \\
\end{tabular}} \\
\hline \multicolumn{8}{|c|}{ ADONEW } & \\
\hline \multicolumn{8}{|c|}{ Shift Handovers Task/Notices Handling } & \\
\hline \multicolumn{8}{|c|}{$\begin{array}{l}\text { (0) Fligth Not defined Objective 1: daily inspection for terminal building } \\
\text { opened by Chiara Leva on the 03-04.2017 : Edit : Close }\end{array}$} & \\
\hline \multirow{2}{*}{\multicolumn{8}{|c|}{$\begin{array}{l}\text { (2) Fligth Not defined Objective 2: Carry out } 2 \text { FOD inspections } \\
\text { opened by Chiara Leva on the 03-042017 ; Edit ; Close }\end{array}$}} & Today Shifts \\
\hline & & & & & & & & ADONEW \\
\hline \multicolumn{8}{|c|}{ ADDHaW } & \\
\hline & & & & & & & & problem with this tak \\
\hline
\end{tabular}

Fig. 2. Example of the main screen with the daily flights to manage and the activities derived from the handovers (shift handovers). 
One of the main advantages of this tool is to give a real picture of routine operations available in a shift versus their timeline. As this data can be used to show a precursor of workload based on the task performed by the resource available in each shift by cumulating the turnaround and routine tasks with the non-recurrent tasks performed during each shift. It was also used to identify latent risks and potential anomalies in the procedures, equipment, training and the human factor component, deviations which otherwise would have never been highlighted as well as providing a lever on the monitoring of key performance in the context of business management for long-term strategies. This leads to improved efficiency and avoids substantial costs that may arise from possible accident scenarios. It can also highlight if there are potential correlations between certain type of issues and different workload levels. Figure 3 and 4 shows a sample of the data analysis function for activities performed for each shifts, and the amount of anomalies recorded for each shift.

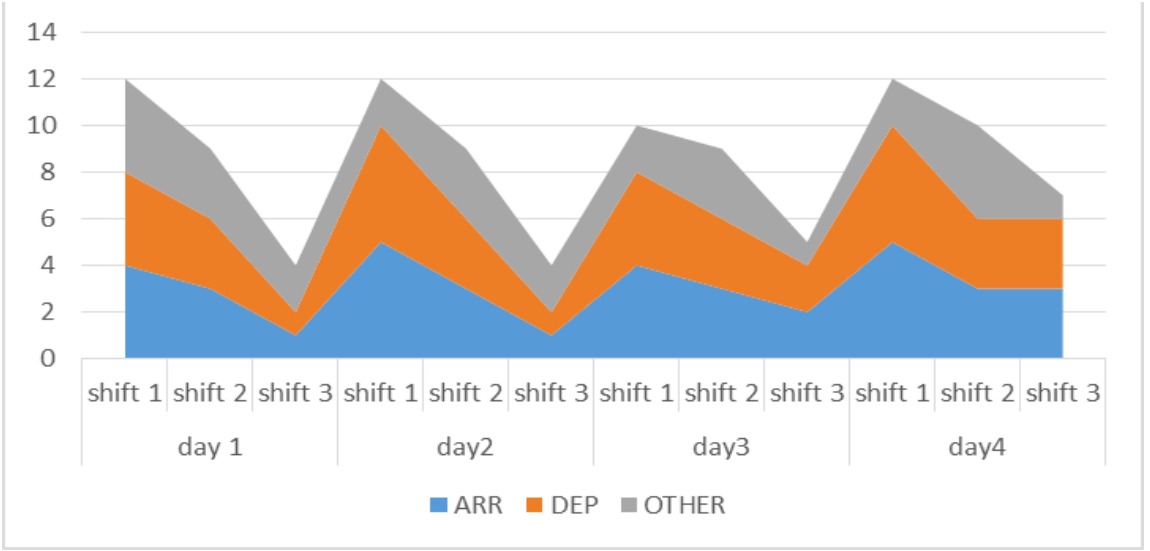

Fig. 3. Example of the analysis for amount of ground handling activities recorded for each shifts coming from different categories.

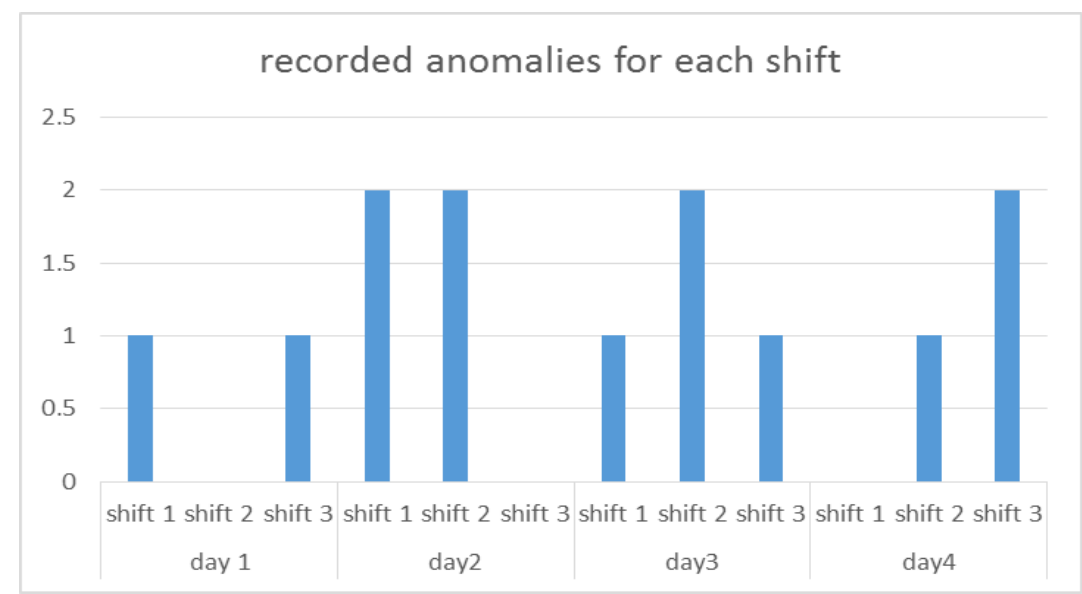

Fig. 4. Example of sample data for amount of anomalies recorded for each shift 
As a byproduct the daily journal also supports better communication as before its introduction some of the operational time was taken up coordinating and passing on information through VHF radio, the workload requirement due to this has greatly decreased. Below some comments received by employees / users of the Daily Journal: "The shift handover has become a mirror for operations activities, even in retrospective mode, with a greater control over the things that we do and that need to be done". Or "now we know better the potential consequences on the next shift if we perform certain operations in a superficial (routine) way". Or "It changed the way we think, we have a bigger awareness and responsibility on our operations". Or "while performing a task, whether the loading of cargo or push-back, now we think about the risks involved in the various steps". For the managers and the operators on shift it is now possible to see over time what was done by whom in each shift and monitor not just the normal activities but also all the extra issues and anomalies that were handled and closed in each shift which added to the actual task requirements.

Regarding competences, the people interviewed were happy with the training provided by the organization and knowing that system would allow them to obtain certifications required and enabled most workers to be flexible and cover many positions. What they pointed out as missing firstly is the monitoring of actual tasks covered to make sure that there is a picture of the workload managed by each operator over time and the skills that need to be retained through experience. This feature of the tool effectively supports performance appraisal and feedback for the workers.

The key success factor in this process of change is the human factor connected to technological development, without a proactive and constructive involvement by the majority of internal staff resistance to change of a work methodology rooted and consolidated over time would have probably compromised the tool uptake even if technically flawless.

There is a development path both technological and human to be undertaken to achieve the improvement of performance and the desired innovation. Some details must be included during this path, such as training, ongoing communication and "no blame policy" towards staff involved in the reporting of errors or irregularities in the process. These are key factors for a successful tool uptake together with process transparency and the involvement of the entire staff.

\section{Day to day task support and the long lasting implications on Error reduction and safety}

The tool needs to support the full cycle for performance management.

The functionalities developed are:

1. Checklist to be used for task support on critical operations available in the on line repository of procedures directly derived from the Process mapping.

2. Digital signoff of the checklist and extra tasks connected to Shift handovers.

3. Review of procedures and processes performing participatory risk assessment (it takes the shape of structured hazard identification exercise focused on each operation of the airport operations manual). This will lead to the initial shaping of a risk registry for the main activities of the company 
to be further updated with risks identified through reporting and periodic reviews.

4. Management of recommendations coming from reporting and updating of risk registry through suggestions of the "Management Review and Safety Board "

5. Monitoring and data analytics capacity on workload managed for each shift over time and recurrent issues (see Figures 3 and 4)

The first two aspects of the tool provide the advantage of making more readily available on the job the forms that can support the workload of the normal daily signed off procedures for all the operators on site. Only now the intention is to perform the sign off closer to real time and support the assignment of the extra tasks as part of the shift handovers notes that can be followed up to monitor task execution and workload precursors (number of activities over time) for shift and operators.

This has dramatically reduced the amount of miscommunication and lack of clarity in respect to who is supposed to do what during the turnaround. The tool contributed to reduce human errors as some of the issues reported were around steps of the tasks that were occasionally previously neglected.

The reduction of human error achieved is estimated to be in the range of $20 \%$ only accounting for the human error that are now reported and corrected on the job while they were previously not even noted (The $20 \%$ accounts for anomalies reported and closed almost immediately, and/or near misses currently recorded).

As an example it is relevant to mention the near misses and anomalies reported around the part of the pushback when the "NOSE GEAR LOCKPIN" is inserted. This pin acts on the valve that inhibits pressure to the nose gear. Then the steering height must be checked so as to avoid the tractor from impacting and damaging the landing gear doors. Possible errors around this part of the task can be forgetting to insert the Lock pin (often detected and corrected immediately before pushback, also thanks to the special notes used in the checklist and on the pushback vehicle, or that during the push, the towing tractor must be maneuvered so as to not exceed the maximum steer radius and speeds; should the safety pin break there would be a loss of directional control.

Furthermore the system has been able to dramatically address the issue of under reporting at the airport. After the first year of using it the airport has been able to increase by a factor of 10 the amount of information reported to management about operational issues [18]. The tool was introduced also to improve reporting levels and address some of the causal factors identified by previous studies for underreporting [19], [20], [21]:

1. a definition of operational anomalies and near misses relevant to the issues normally encountered on everyday tasks

2. a reporting framework that can avoid the extra paperwork

3 . the provision of feedback on reported problems and operational issues.

The new reporting framework introduced in this change initiative linked the effect of an online task support to support the management of workload for highly proceduralised tasks in the form of a check list with an embedded reporting function (that is inherent to the signoff process already part of on-site operational requirements). The advantage of using existing tools for near misses and in general 
event reporting is that the use of ad hoc reporting forms fail to provide a real-time picture of routine operations and possible peaks of task requirements due to anomalies and disturbances to be managed in the process [22].

\section{Interim Results and future work}

The new task support tool and reporting framework introduced in this change initiative has the advantage of being based on the forms that were already used as part of the normal daily operations for all the operators on site.

This advantage effectively helped the goal of providing a real-time support and a picture of routine operations aimed at performance improvement and predictive risk management. As already stated the checklists were used as a real time sign off for the tasks and delivered workload management support as they reminded key steps in detail and gave the possibility to report quickly any possible anomaly or issue in carrying out the tasks. Furthermore the shift handover page was designed to give the possibility to allocate tasks outside peak time, check status quickly and report once again issues as they arise. Therefore the new tool presented the advantage of seamlessly integration in a pre-existing workflow.

The data collected through it have the potential to identify latent hazards in tasks, equipment, and procedures that may otherwise go unnoticed, and will also provide a better overview of everyday performance in the context of growing airport traffic demand. In the first months after its introduction was already able to change the rate of reporting from 40 accidents reports in 6 years to 209 anomalies collected with the trip file plus 201 activities reported through the shift handover in 1 month. Key success factors in this process have been:

1. Enthusiasm and proactive attitude of many ramp/operational agents; the desire for a change of work methodology and a new way of supporting their daily activities and the appraisal of their performance, different from the obsolete methods of evaluation.

2. Top management continuous support, proactive and positive attitude towards the initiative. That also led the management to use the tool to allocate tasks on shift handovers considering the workload already shouldered in each shift (related to the amount of turnarounds to be handled).

3. The possibility of keeping records of data collected over time; an overall evaluation of all processes of work and evidence of good performance and possible anomalies leading to integrated data monitoring.

The support of training sessions on "human factor issues" were organized in connection with the introduction of the new tool in the airport among which the exchange of information for the turnaround process between ramp operators and check in and gate operators. The feedback received was very positive and, it is perhaps interesting to report comments made by some of the Ramp operators: "by working on these check-lists and filling up the form with the tasks and the name of the agent who carried out the activities, we have become more conscious on our role and we have gone "back to the basics of our tasks", or "It is something everyone sees, something everyone deals with everyday but when you change your perspective 
and method of working (eg. with the Daily Journal) or perform a risk assessment by working as a team with different departments, (as done during the Human Factor training sessions) something begins to change as if you were suddenly awakened".

\section{"The DJ provides benefits for task support on site"}

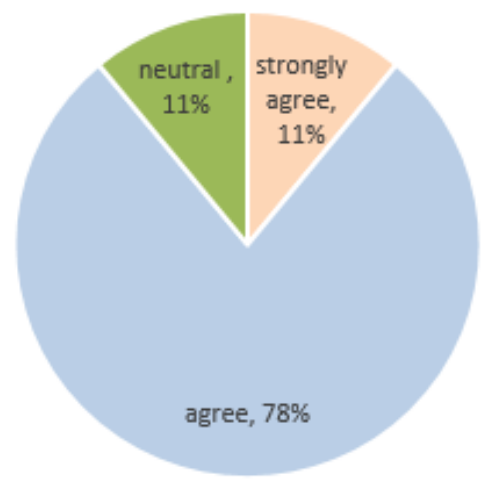

" strongly agree " agree " neutral $=$ disagree " strongly disagree

Fig. 5. Example of feedback collected from the operators about task support provided

The interim successes are a very important part of the initiative. As Kotter (1995) noted "Real transformation takes time and a renewal effort risks losing momentum if there are no short-term goals to meet. Without short-terms wins, too many people give up or actively join the ranks of those people who have been resisting change" [23]. The tool can have the long lasting implications to support the achievement of improvement and leverage on the every-day performance within the context of the long term strategy of growth pursued by the airport, were the human factors and the capacity to deal effectively with required workload are key. However in the next stage of the project we now need to actually assess workload levels for primary tasks measures and see how the tool can be used to monitor workload, human error and guide management in assigning extra tasks during less busy times to avoid peaks of workload requirements. For the subsequent stage of the project therefore formal methods to assess current perceived workload for different shift conditions and different roles will be deployed using the NASA TLX as a starting point [24] and moving progressively if needed towards more advanced models [25] [26] also able to discriminate between different types of activities (e.g. pushback or baggage handling are tasks associated with different cognitive workload demands). In choosing the appropriate methodology for the next stage the criteria of validity (i.e. to determine whether the Workload measurement instrument is actually what extent a method can explain objective performance measures, such as task execution time) and sensitivity (i.e. the capability of a method to discriminate significant variations in workload and changes in resource demand or task difficulty) [27]. The assessment will be focusing on primary task performance and it is important to remember that given the 'live' 
context we can not impact negatively on operators' functioning as the main goal is to achieve an even better level of support for human performance and an improved understanding of the key drivers behind it.

\section{References}

1. Irish Aviation Authority. (2017). Ground Operations. Retrieved 13 January 2017, from https://www.iaa.ie/commercial-aviation/ground-operations

2. Stanton N., Salmon P., G. Walker, C. Baber, D. Jenkins (2010) Human Factors Methods: a Practical Guide for Engineering Design. Ashgate, Burlington, VA

3. Bommer S.C., Fendely M. (2016). A theoretical framework for evaluating mental workload resources in human systems design for manufacturing operations. International Journal of Industrial Ergonomics. Available online 5 November 2016

4. DiDomenico A., Nussbaum M., (2011). Effects of different physical workload parameters on mental workload and performance. Int. J. Ind. Ergonomics, 41 (3) (2011), pp. 255-260

5. Embrey, D., Blackett, C., Marsden, P., Peachey, J., Development of a Human Cognitive Workload Assessment Tool. Dalt. Hum. Reliab. Assoc. (2006)

6. Meyer, D., \& Kieras, D. A Computational Theory of Executive Cognitive Processes and Multiple-Task Performance: Part 1. Basic Mechanism. Psychology Review, 104, 3-65 (1997)

7. Ackerman, P. L. Determinants of Individual Differences During Skill Acquisition: Cognitive Abilities And Information Processing. Journal of Experimental Psychology: General, 117, 288-318 (1988)

8. Borkowski, J. G., \& Burke, J. E. Theories, Models, and Measurements of Executive Functioning: an Information Processing Perspective. In G. R. Lyon \& N. A. Krasnegor (Eds.), Attention, memory, and executive function. 235-261 (1996)

9. Leva, M. C., Kay, A. M., Mattei, F., Kontogiannis, T., Ambroggi, M., \& Cromie, S. (2009). A dynamic task representation method for a virtual reality application. In Engineering psychology and cognitive ergonomics, Berlin Heidelberg: Springer.

10. National Transportation Safety Board. (1988). Aircraft accident report, NTSB/AAR-88/05. Washington, DC. Retrieved 2 February 2017, from https://www.ntsb.gov/investigations/ AccidentReports/Pages/AAR8805.aspx

11. Degani, A., \& Wiener, E. L. The Human Factors of Flight-Deck Checklists: The Normal Checklist (NASA contractor report 177549). Moffett Field, CA: NASA Ames Research Center (1990)

12. British Petroleum, Fatal Accident Investigation report - Isomerization Unit Explosion Final Report -Texas City, Texas, USA (2005)

13. The Health and Safety Executive. (2003). Reducing Error and Influencing Behaviour. Retrieved 19 January 2017, from http://antarisconsulting.com/docs/guides/unit_a/ A7_HSG48_Reducing_Error_and_Influencing_Behaviour.pdf

14. Aviation Safety Reporting System, NASA. (2015). Callback, a checklist, issue 428. Retrieved 17 January 2017, from https://asrs.arc.nasa.gov/publications/callback.html

15. Longo, L. Designing medical interactive systems via assessment of human mental workload. CBMS'15: Proceedings of the 2015 IEEE 28th. International Symposium on Computer Based Medical Systems, pp.364-365. Doi.10.1109/CBMS.2015.67. (2015).

16. Leva, M.C., Naghdali F., Balfe, N., Gerbec, M. and Demichela M. Remote Risk Assessment: A Case Study using SCOPE Software. CHEMICAL ENGINEERING TRANSACTIONS, ISSUE N 43. (2015) 
17. Leva, M. C., Sordo, D., Mattei, F. Performance Management in a Small Regional Airport: The role of change in the Day to Day task support for an integrated SMS. Journal Cognition, Technology and Work archive Volume 17 Issue 2. 237-248 (2015)

18. ICAO. (2009). Safety Management Manual (SMM) Doc 9859 AN/474. Retrieved 31 January 2017, from http://www.icao.int/safety/SafetyManagement/Documents/Doc. 9859.3rd\%20Edition.alltext.en.pdf

19. Airport Council International (2006) Airport Benchmarking To Maximise Efficiency. Published By ACI World Headquarters Geneva - Switzerland.

20. Pransky, G., Snyder, T., Dembe, A., Himmelstein, J., 1999. Under-reporting of workrelated disorders in the workplace: a case study and review of the literature. Ergonomics 42, 171-182.

21. Clancy P, Leva M.C., Hrymak V., Sherlock M.. 2011 Safety and or hazard near miss reporting in an international energy company. Proceedings of the Irish Ergonomics Society Annual Conference 2011 Edited by Leonard W. O'Sullivan and Chiara Leva ISSN 1649210.

22. Leva M.C Cahill J Kay A Losa G. Mc Donald N. 2010 The Advancement of a New Human Factors Report - 'The Unique Report' - Facilitating Flight Crew Auditing of Performance/Operations, as part of an Airline's Safety Management System. Ergonomics Feb;53(2):164-83.

23. Kotter, J. P. (1995, Mar-Apr). Leading change: Why transformation efforts fail. Harvard Business Review, Vol. 73, No. 2, March/April, pps. 59-67.

24. Hart, S. G.; Staveland, Lowell E. (1988). "Development of NASA-TLX (Task Load Index): Results of Empirical and Theoretical Research". In Hancock, Peter A.; Meshkati, Najmedin. Human Mental Workload (PDF). Advances in Psychology. 52. Amsterdam: North Holland. pp. 139-183. doi:10.1016/S0166-4115(08)62386-9.

25. Longo, L.: A defeasible reasoning framework for human mental workload representation and assessment. Behaviour and Information Technology 34(8), 758-786 (2015)

26. Rizzo L., Dondio P., Delany S.J., Longo L. (2016) Modeling Mental Workload Via RuleBased Expert System: A Comparison with NASA-TLX and Workload Profile. In: Iliadis L., Maglogiannis I. (eds) Artificial Intelligence Applications and Innovations. AIAI 2016. IFIP Advances in Information and Communication Technology, vol 475. Springer. 